\title{
The Influence of the Rotating Piston Height on the Driving Power of a Rotating
} Machine with Profiled Rotors

\author{
M. M. Stoican (Prisecaru) ${ }^{1}$, N. Băran ${ }^{2} \&$ A. Almaslamani ${ }^{3}$ \\ ${ }^{l}$ PhD Student, ${ }^{2}$ Prof. Dr. Eng., ${ }^{3}$ PhD Student, Faculty of Mechanical Engineering and Mechatronics, Department of Thermodynamics, Engines, Thermal and \\ Refrigerating Equipment's, ${ }^{1}$ University Politehnica of Bucharest, ROMANIA. \\ Email: mirela.prisecaru@yahoo.com ${ }^{I}, n \_b a r a n \_f i m m @ y a h o o$. com $^{2} \&$ ammar.fadhils8@yahoo.com ${ }^{3}$
}

\section{ABSTRACT}

The paper presents the operating principle and the constructive solution of a rotating machine with two profiled rotors. The influence of the rotating piston height on the driving power of the machine is revealed.

Keywords: Rotating Piston, Machine with Profiled Rotors.

\section{INTRODUCTION}

The present paper continues the theoretical and experimental researches on rotating machines with profiled rotors.

The machines are used to convert the energies from one form to another with the help of a movable member (piston, profiled rotor or blade) [1], [2].

The machines, according to their purpose, are divided into two categories [1], [2], [3], [4]:

1. Power machines (motor machines), which convert a certain form of energy into mechanical energy (internal combustion engines, steam or gas turbines, etc.).

2. Working machines, which convert mechanical energy into potential pressure energy (fans, pumps, compressors). A constructive solution for fluid handling, which can be used as a "reversible machine", is presented as follows:

I. If the pressure of the fluid entering the machine $\left(\mathrm{p}_{1}\right)$ is lower than the pressure at the discharge $\left(\mathrm{p}_{2}\right)$ then the machine can be used as a working machine i.e.: as a pump, fan or low pressure compressor.

II. If $\mathrm{p}_{1}$ is greater than $\mathrm{p}_{2}$, the machine can be used as a force machine, namely: steam engine, combustion engine, pneumatic engine, hydrostatic engine.

The analyzed constructive solution is based on a patent and was designed, planned and built in the laboratories of the Department of Thermotechnics, Engines, Thermal and Refrigeration Equipment's of the University Politehnica of Bucharest.

The paper addresses the first class, namely, as a working machine; a constructive solution of a rotating volumetric pump with profiled rotors is analyzed.

Such a type of working machine must ensure the transformation of the useful moment received from the shaft, into potential pressure energy, the transformation taking place with minimal losses.

Table 1 presents the classification of rotating machines with profiled rotors according to the adopted constructive solution [1]. 
Table 1: Classification of Rotating Machines with Profiled Rotors

\begin{tabular}{|l|l|l|}
\hline \multirow{4}{*}{$\begin{array}{l}\text { Rotating } \\
\text { machines } \\
\text { with profiled } \\
\text { rotors }\end{array}$} & Classification by purpose & Classification by the constructive solution \\
\cline { 2 - 3 } & \multirow{3}{*}{ Working machines } & Pumps for driving fluids or with suspensions \\
\cline { 3 - 3 } & \multirow{2}{*}{ Power machines } & Fans for transporting gases or vapours \\
\cline { 3 - 3 } & & Blowers for gas and vapour compression \\
\cline { 3 - 3 } & & Pneumatic motors \\
\cline { 3 - 3 } & & Steam engine or combustion gases \\
\hline
\end{tabular}

2. THE CONSTRUCTIVE SOLUTION AND THE OPERATING PRINCIPLE OF THE ROTATING VOLUMETRIC MACHINE

The machine consists (figure 1) of two identical rotors $(2,5)$ of special shape that rotate at the same speed inside some housings $(1,4)$. The synchronous rotation of the rotors is ensured by two gear wheels fixed on shafts 7 and 9 .

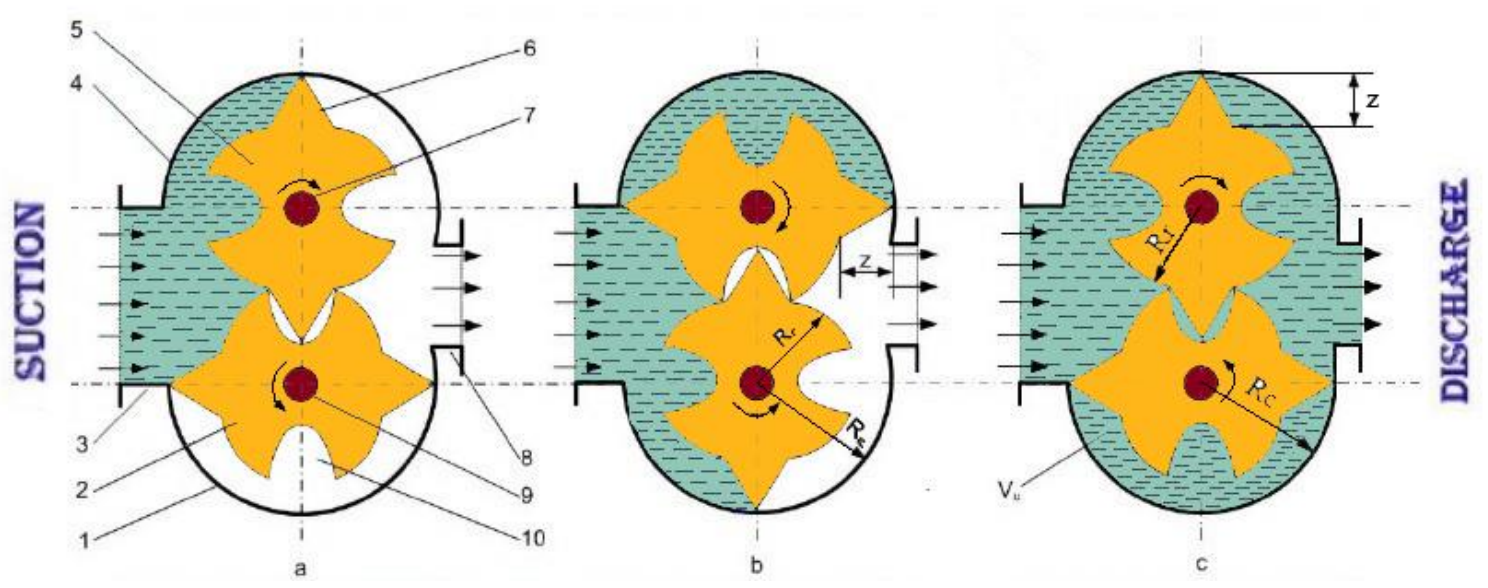

Figure 1: After a Rotation of 90 Degrees the Rotors Occupy Positions a, b, c

1 - lower housing; 2 - lower rotor; 3 - fluid suction chamber; 4 - upper housing; 5 - upper rotor; 6 - rotating piston of the upper rotor; 7 - driven shaft; 8 - fluid discharge chamber; 9 - driving shaft; 10 - cavity in which the piston of the upper rotor enters

The aspirated fluid (figure 1.a) is transported to the discharge and after a rotation of $90^{\circ}$ of both rotors; the situation in figure 1.b is reached and later the one in figure 1.c.

\subsection{Establishing the Calculation Relation of the Flow Rate Driven by the Machine}

After a rotation of $180^{\circ}$ the fluid in the useful volume $V_{u}$ (figure 1.c), that is, in the space between the pistons, the lower housing (1) and the lower rotor (2), will be sent to the discharge chamber (8). At a complete rotation of the shafts $(7,9)$, two such volumes will be transported from the suction to the discharge [1]. 
$\dot{V}_{u}=2\left(\frac{\pi R_{c}^{2}}{2}-\frac{\pi R r^{2}}{2}\right) \cdot l \quad\left[m^{3} / r o t\right]$

The housing radius $\left(R_{c}\right)$ is the sum of the rotor radius $\left(R_{r}\right)$ and the piston height $(z)$.

$$
R_{c}=R_{r}+z \quad[m]
$$

From equation (1) and equation (2) results:

$$
\dot{V}_{u}=\pi l \mathrm{z}\left(\mathrm{z}+2 \mathrm{R}_{\mathrm{r}}\right) \quad\left[m^{3} / r o t\right]
$$

The volumetric flow rate of fluid flowed by a single rotor of length $1[\mathrm{~m}]$ and speed $\mathrm{n}_{\mathrm{r}}$ [rot / $\left.\mathrm{min}\right]$ will be:

$$
\dot{V}_{u}=\pi l z\left(z+2 R_{r}\right) \cdot \frac{n_{r}}{60}\left[m^{3} / s\right]
$$

Because the machine has two identical rotors, the fluid flow rate transported by the machine will be:

$$
\dot{V}_{m}=2 \dot{V}_{m}=\pi l z\left(z+2 R_{r}\right) \cdot \frac{n_{r}}{30}\left[m^{3} / s\right]
$$

\subsection{Establishing the Calculation Relation of the Driving Power of the Machine}

The driving power of the machine will be [5] [6]:

$P=\dot{V} \cdot \Delta p \quad[W]$

where:

$* \dot{V}-$ volumetric flow rate driven by the machine $\left[\mathrm{m}^{3} / \mathrm{s}\right]$;

$* \Delta \mathrm{p}$ - increase in pressure between suction and discharge $\left[\mathrm{N} / \mathrm{m}^{2}\right]$.

From relations (5) and (6) one can obtain:

$P=\pi l z\left(z+2 R_{r}\right) \cdot \frac{n}{30} \cdot \Delta p \quad[W]$

The increase in pressure achieved by the pump $(\Delta \mathrm{p})$ can also be expressed according to the geodesic pumping height $\left(\mathrm{H}_{\mathrm{g}}\right)$ of the water [7] [8] [9]:

$$
\Delta p=\rho_{\mathrm{H}_{2} \mathrm{O}} \cdot g \cdot H_{g} \quad\left[N / m^{2}\right]
$$

as a result:

$$
\begin{aligned}
& P=\dot{V} \cdot \rho_{\mathrm{H}_{2} \mathrm{O}} \cdot g \cdot H_{g} \quad[W] \\
& P=\pi l z\left(z+2 R_{r}\right) \cdot \frac{n_{r}}{30} \cdot \rho_{\mathrm{H}_{2} \mathrm{O}} \cdot g \cdot H_{g} \quad[W]
\end{aligned}
$$


From the relation (10) one can observe that the driving power of the machine varies according to the following parameters: (1) Constructive parameters: 1 - rotor length [m]; $\mathrm{R}_{\mathrm{r}}$-rotor radius [m]; $\mathrm{z}$ - rotating piston height [m], (2) Functional parameters: $\mathrm{n}$ - machine speed [rot / min]; $\mathrm{H}_{\mathrm{g}}$ - pump pressure increase (geodesic height).

\section{ESTABLISHING THE CONNECTION RELATION BETWEEN THE DRIVE POWER AND THE ROTATING PISTON HEIGHT}

If in the relation:

$$
P=\pi l z\left(z+2 R_{r}\right) \cdot \frac{n_{r}}{30} \cdot \Delta p \quad[W]
$$

the derivative is performed: $P^{\prime}=f(z)$ one can obtain:

$$
z=R_{r}
$$

that is to say, the driving power is maximum if the piston height is equal to the rotor radius; theoretically it is correct, in fact $z<R_{r}$.

The relation (11) is written as follows:

$$
\begin{aligned}
& P=\pi l\left(z^{2}+2 z^{2}\right) \cdot \frac{n_{r}}{30} \cdot \Delta p \quad[W] \\
& P=\pi l z^{2} \cdot \frac{n_{r}}{10} \cdot \rho_{H_{2} O} \cdot g \cdot H_{g} \quad[W]
\end{aligned}
$$

The following shall be considered $\mathrm{l}=\mathrm{kz}, \mathrm{k}=1$ and one can obtain:

$$
\begin{aligned}
& P=\pi z^{3} \cdot \frac{n_{r}}{10} \cdot 10^{3} \cdot 10 \cdot H_{g} \quad[W] \\
& P=\pi \cdot n_{r} \cdot H_{g} \cdot z^{3} \quad[\mathrm{~kW}]
\end{aligned}
$$

$\mathrm{n}_{\mathrm{r}}=500[\mathrm{rot} / \mathrm{min}], \mathrm{H}_{\mathrm{g}}=10\left[\mathrm{mH}_{2} \mathrm{O}\right]$ is chosen and results:

$$
P=15700 \cdot z^{3} \quad[k W]
$$

By introducing in relation (17) the theoretical values of the existing rotor radius in the laboratory $\left(R_{r}=5 \cdot 10^{-2} \mathrm{~m}\right)$, the data in Table 2 are obtained.

Table 2: Values for $\mathrm{z}$ and $\mathrm{P}$

\begin{tabular}{|l|l|l|l|l|l|}
\hline $\mathbf{Z}[\mathrm{m}]$ & 0.01 & 0.02 & 0.03 & 0.04 & 0.05 \\
\hline $\mathbf{P}[\mathrm{kW}]$ & 0.0157 & 0.1256 & 0.4239 & 1.004 & 1.962 \\
\hline
\end{tabular}


Based on the data in table 2 , the function $\mathrm{P}=\mathrm{ct} \cdot \mathrm{z}^{3}$ in figure 2 was plotted.

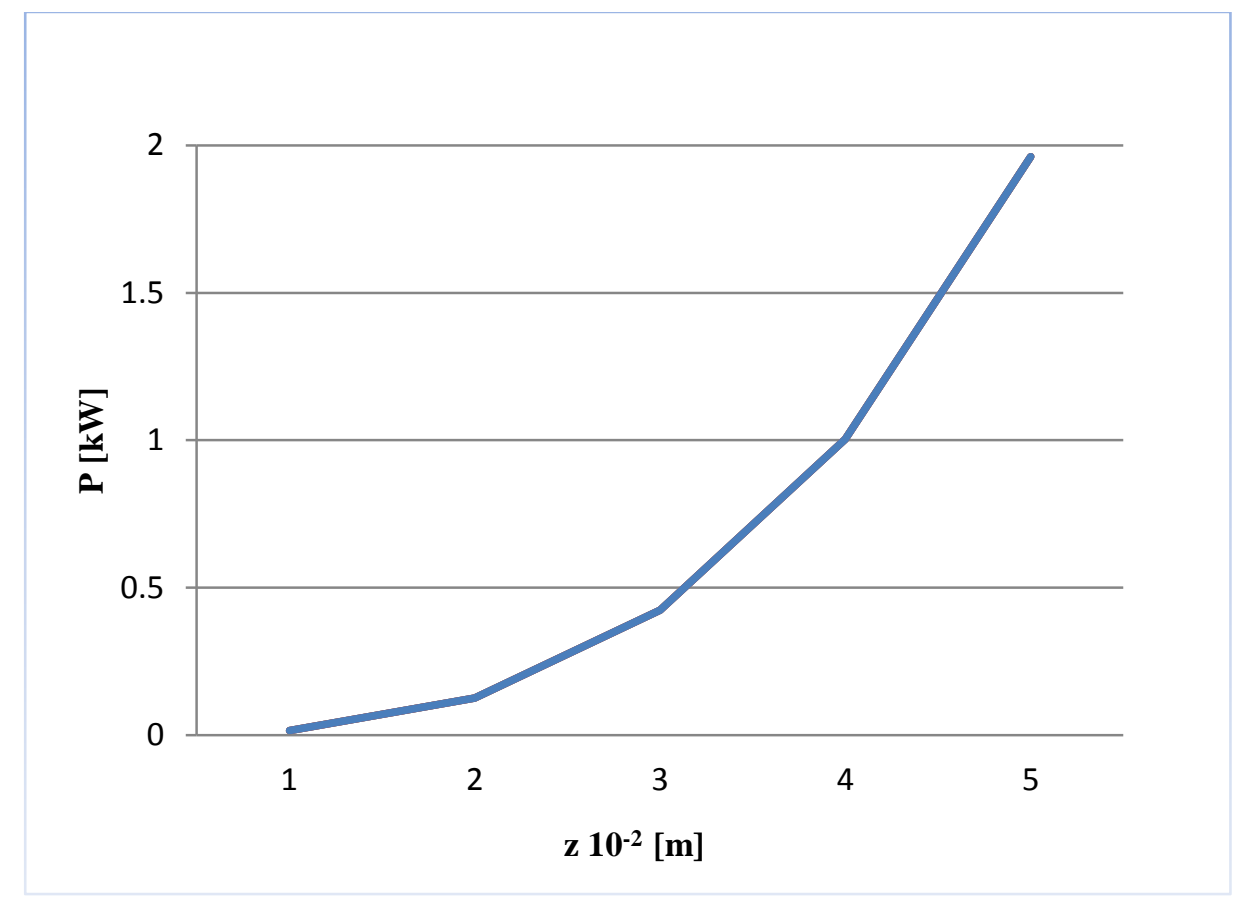

Figure 2: Graphical Representation of the Function $\mathrm{P}=\mathrm{ct} \cdot \mathrm{z}^{3}$

From figure 2 one can observe that the driving power of the machine increases exponentially with the value of $\mathrm{z}$.

Depending on the execution technology available to the beneficiary, for a certain flow rate driven by the machine, 1 is chosen, then $R_{r}$ and $z$.

\section{CONCLUSION}

1. From the above it is found that the driving power of the rotating working machine depends essentially on the height of the rotating piston $(\mathrm{z})$.

2. The value of $\mathrm{z}$ is slightly smaller than the rotor radius $\left(\mathrm{R}_{\mathrm{r}}\right)$, because the shaft that drives the rotor can be coupled with a rotor flange, it is not obligatory for the shaft to cross the rotor.

3. After specifying $1, R_{r}, z$, there is a computation program [10] that gives the contour coordinates of a rotor; the two rotors are identical.

4. The change of the volumetric flow rate of the rotating machine is made by changing the speed of the engine driving the machine.

5. This rotating machine can carry multiphase fluids, viscous fluids; as a result, it can be used in the fields of energy, petrochemical, food, agriculture.

\section{REFERENCES}

[1] N. Băran, P. Răducanu, et. al., "Bases of Technical Thermodynamics", Politehnica Press Publishing House, Bucharest, 2010. 
[2] M. Hawas, PhD Thesis, "The influence of fluid viscosity on the performance of rotating machine with profiled rotors", Universitatea Politehnica din București 2015, Romania.

[3] M. Exarhu, "Pneumatic and hydraulic machine and installations", (in Romanian), SC. ANDOR SRL, Bucharest, 2011.

[4] A. Motorga, "Influence of constructive and functional parameters on the performances of rotating machines with profiled rotors", PhD Thesis, Faculty of Mechanical Engineering and Mechatronics, Politehnica University of Bucharest, 2011.

[5] N. Băran, D. Duminică, D. Besnea, A. Detzortzis, "Theoretical and Experimental Researches Regarding the Performances of a New Type of Rotating Machine with Profiled Rotors", Advanced Materials Research, Switzerland, vols. 488-48, 2012, pp.1757-1761.

[6] N. Băran, I. Căluşaru, A. Detzortzis, "Research Regarding the Testing of a New Type of Rotating Machine with Profiled Rotors", Journal of Materials Science and Engineering A 2 (3) 372-376, 2012, pp. 372-376.

[7] E. Isbășoiu, “Treatise on fluid mechanics”, (in Romania), AGIR Publishing House Bucharest, 2011.

[8] G. Bar Meir, "Basics of fluid mechanics”, North Washtenaw Ave Chicago, IL, 2013.

[9] S. Nazarenko, "Fluid Dynamics via Examples and Solution”, CRC Press (Taylor \& Francis Group), 2014.

[10] N. Băran, D. Besnea, A. Motorga, "Elements of computing the architecture and manufacturing technology for a new type of profiled rotor", Proceedings International Conference, $6^{\text {th }}$ Workshop on European Scientific and Industrial Collaboration on promoting Advanced Technologies in Manufacturing, WESIC'08, Bucharest, 2008, pp. 233-241. 